\title{
Planning and development in the context of Mozambique, Ecuador, Bolivia and Brazil
}

\author{
EDITORIAL
}

Anderson Catapan

This editorial presents the papers of the fourth issue of the seventh volume of the Revista Brasileira de Planejamento e Desenvolvimento - Brazilian Journal of Planning and Development (RBPD). This number brought contributions to the planning and development, as well as in previous numbers of this period, of teachers from Brazil and several other countries.

The first article by Zidora et al. (2018) analyzes the role of contracts as well as collective actions in the production and marketing of maize in the context of Mozambique. Then, Mileu and Queróz (2018) study a qualitative risk model.

Bandeira, Guedes and López-Parra (2018) analyze the development and territory in the context of Ecuador. In the fourth article, Lopes, Basso and Hübner (2018) address the school feeding program in Bolivia and Brazil.

The next article, signed by Ribaski et al. (2018) presents a discussion on sustainable development in Rio Grande do Sul. The sixth article of Hervías (2018) discusses family organizations for social and gender development.

Then, Müller et al. (2018) talk about cyanobacteria and cyanotoxins in the chemical treatment of water. In the eighth and last text of this edition, Barbosa et al. (2018) address Copel's consolidation of electrification in Maringá.

We would like to thank the contribution of all the authors and evaluators of our journal. Introducing the articles of this issue, we wish a great and profitable reading to all !!! 